\title{
Can pulmonary conduit dysfunction and failure be reduced in infants and children less than age 2 years at initial implantation?
}

Tara Karamlou, MD, ${ }^{\mathrm{a}, \mathrm{b}}$ Eugene H. Blackstone, MD, ${ }^{\mathrm{b}}$ John A. Hawkins, MD, ${ }^{\mathrm{c}}$ Marshall L. Jacobs, MD, ${ }^{d}$ Kirk R. Kanter, MD, ${ }^{\mathrm{e}}$ John W. Brown, MD, ${ }^{f}$ Constantine Mavroudis, MD, ${ }^{9}$ Christopher A. Caldarone, MD, ${ }^{a}$ William G. Williams, MD, ${ }^{a}$ Brian W. McCrindle, MD, MPH, and the Pulmonary Conduit Working Group* for the members of the Congenital Heart Surgeons Society

Supplemental material is available online.
From the Division of Cardiovascular Surgery and Cardiology, Hospital for Sick Children, Toronto, Ontario, Canada ${ }^{\text {aa }}$, the Department of Cardiothoracic Surgery and Quantitative Health Sciences, Cleveland Clinic Foundation, Cleveland, Ohio ${ }^{\mathrm{b}}$; the Department of Pediatric Cardiothoracic Surgery, Primary Children's Medical Center, Salt Lake City, $\mathrm{Utah}^{\mathrm{c}}$; the Division of Cardiothoracic Surgery, St Christopher's Hospital for Children, Philadelphia, $\mathrm{Pa}^{\mathrm{d}}$; the Division of Pediatric Cardiac Surgery, Emory University School of Medicine, Atlanta, $\mathrm{Ga}^{\mathrm{e}}$; the Department of Surgery, Indiana University, Indianapolis, Ind ${ }^{\mathrm{f}}$; and the Department of Cardiothoracic Surgery, Children's Memorial Hospital, Chicago, Ill. ${ }^{g}$

This study was supported, in part, by a grant from the Children's Heart Foundation.

Read at the Eighty-sixth Annual Meeting of The American Association for Thoracic Surgery, Philadelphia, Pa, April 29-May 3, 2006.

Received for publication April 27, 2006; revisions received June 1, 2006; accepted for publication June 16, 2006.

Address for reprints: Brian McCrindle, MD, MPH, The Hospital for Sick Children, 555 University Ave, Toronto, Ontario, Canada M5G 1X8 (E-mail: brian.mccrindle@ sickkids.ca).

*Members listed individually under acknowledgements.

J Thorac Cardiovasc Surg 2006;132:829-38

$0022-5223 / \$ 32.00$

Copyright $(\odot) 2006$ by The American Association for Thoracic Surgery

doi:10.1016/j.jtcvs.2006.06.034
Objectives: We sought to examine risk factors for pulmonary conduit failure or dysfunction in infants less than age 2 years at initial implantation.

Methods: From 2002 to 2005, 241 children at 17 institutions were discharged alive after initial pulmonary conduit insertion. Initial conduit type was pulmonary allograft in $37 \%$, aortic allograft in $29 \%$, bovine jugular venous valved conduit in $25 \%$, porcine heterograft in $2 \%$, and decellularized allograft in $7 \%$. Parametric hazard analysis determined time-related prevalence and associated risk factors for pulmonary conduit intervention and explantation. Serial echocardiographic measurements after conduit implant were analyzed by mixed regression models.

Results: There were 89 first conduit-related interventions after discharge and 37 intial conduit explants were performed. First conduit intervention occurred at a constant rate, with a prevalence of 58\% at 3 years from initial implant. Pulmonary conduit explantation (30\% at 3 years) was characterized by an early-rising risk, suggesting that catheter-based intervention effectively blunts this early initial risk. Common risk-factors for first conduit intervention and explantation were smaller conduit Z-score and younger age at initial conduit implant, and the presence of pulmonary arborization abnormalities or stenoses. Pulmonary conduit peak gradient and regurgitation progressed nonlinearly in all patients over time. Gradient progressed more rapidly in children with aortic allografts and when initial conduit Z-score was less than +1 or more than +3 . Pulmonary conduit regurgitation also progressed more rapidly in children with initial conduit Z-score greater than +3 and in those without jugular venous valved conduits, especially aortic allografts.

Conclusions: Pulmonary conduit durability and hemodynamic function in patients undergoing initial conduit insertion at less than age 2 years can be improved by using pulmonary conduits with Z-scores between +1 and +3 .

$\mathrm{V}$ alved conduits from the ventricle to the pulmonary arteries (pulmonary conduit; PC) have a high failure and intervention rate in infants and young children. ${ }^{1-3}$ Although a variety of PC types are available, the optimal prosthesis choice for PC performance and patient outcome is unknown. ${ }^{1-7}$ The Congenital Heart Surgeons Society (CHSS) undertook a multi-institutional, prospective study to characterize PC durability and dysfunction as delineated by echocardiography in children under age 2 years at initial implantation.

\section{Materials and Methods \\ Patients}

From 2002 to 2005, 241 children at 17 CHSS institutions were discharged alive after initial PC insertion at age less than 2 years and were enrolled in a prospective observational study. 


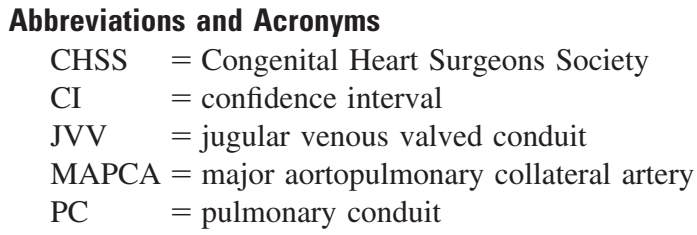

Exclusion criteria included the following: non-biventricular repairs, ventricular septal defect fenestration, PC placement without ventricular septal defect closure, or nonvalved conduits. This study was approved by all institutional review boards and informed parental consent was obtained. Patient characteristics and PC types are given in Table EI.

\section{Data Collection}

Data abstracted by CHSS data center staff were obtained from medical records for all admissions, operations, diagnostic and interventional catheterizations, echocardiograms, and autopsies. Cross-sectional follow-up was performed between August and September 2005 and was complete for $89 \%$ of the cohort. Data abstracted included patient and procedural characteristics, PC features, allograft donor information, and longitudinal assessment of PC stenosis and regurgitation. Pulmonary artery and ventricular echocardiographic dimensions were converted into Z-scores by regression equations based on previously published nomograms. ${ }^{8,9}$

Catheter-based interventions and PC repairs were classified as PC-related, non-PC-related, pulmonary artery interventions, and left heart interventions. Adjudication of PC and non-PCrelated interventions were made by panel review of diagnostic and procedural reports. Study end points were first PC-related intervention (catheterization or surgical) and conduit durability (time to explantation).

\section{Data Analysis}

Data are given as frequency, median with range, or mean \pm standard deviation as appropriate, with the number of nonmissing values indicated. All data analyses were performed with SAS statistical software (version 9.1; SAS Institute, Inc, Cary, NC). Initial events, using PC implant date as time zero, were modeled as time-dependent events by using both Kaplan-Meier estimates and parametric methods, with the association with risk factors being explored in multivariable parametric analysis as previously described. ${ }^{10,11}$

Serial echocardiographic measurements obtained from reports (occurring before any PC intervention) of Doppler peak instantaneous PC gradient and subjective grade of PC regurgitation were modeled, and risk factors were sought by using general linear mixed regression models and general estimating equations. Univariable exploratory plots were generated initially to determine the longitudinal relationship (eg, linear, quadratic, cubic) between each potential predictor and outcome. Factors were then entered by a stepwise selection algorithm, with interaction terms added in a hierarchical manner. For the mixed linear regression models, candidate covariance structures were tested explicitly with the final matrix selected on the basis of variograms and minimization of the

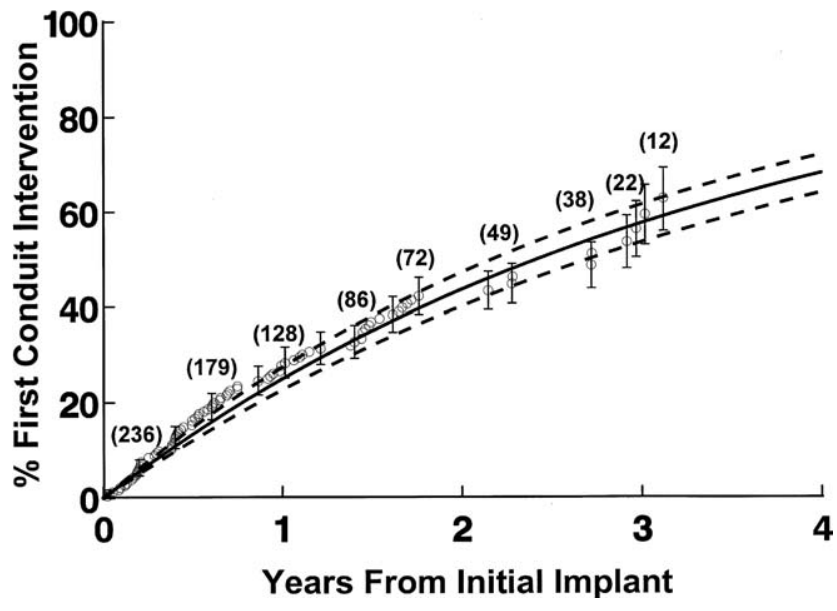

Figure 1. First conduit-related intervention after initial implantation. Each symbol represents an intervention: vertical lines are asymmetric confidence limits (CLs) equivalent to 1 standard error $(68 \%)$; numbers in parentheses are children remaining at risk; solid lines are parametric estimates enclosed in dashed $68 \%$ CLs.

information criteria (AIC and BIC) generated from PROC MIXED. PC subjective regurgitation grade was modeled as an ordinal outcome (graded as none, trivial, mild, moderate, or severe), and the assumption of proportional odds was verified with cumulative logit plots. Time zero was taken to be the date of PC implant, so that only postoperative values and those occurring before any PC-related intervention $(\mathrm{n}=729)$ were used. However, preoperative values (as time independent covariables) were investigated as potential predictors in all models.

\section{Results}

There were 280 PCs placed in 241 patients during the study period. Five patients have died, and 150 currently remain free of any PC-related intervention after initial PC placement (Figure E1).

\section{Conduit-related Initial Interventions}

Of the 241 patients, 89 underwent a first intervention after discharge from the hospital; 63 interventions were catheterbased, 1 PC was surgically repaired, and 25 were explanted. Prevalence of first PC intervention was $25 \%$ (70\% confidence intervals (CIs): $23-27 \%$ ) and 58\% (70\% CIs: 54-62\%) at 1 and 3 years, respectively, Figure 1. Initial interventions occurred frequently and at a constant hazard rate from initial PC implant.

\section{Conduit Explantation}

There were 37 initial PCs explanted during the study period; 25 explantations occurred without prior intervention and 12 occurred after either a catheter-based procedure or repair. Primary reasons for explantation included 


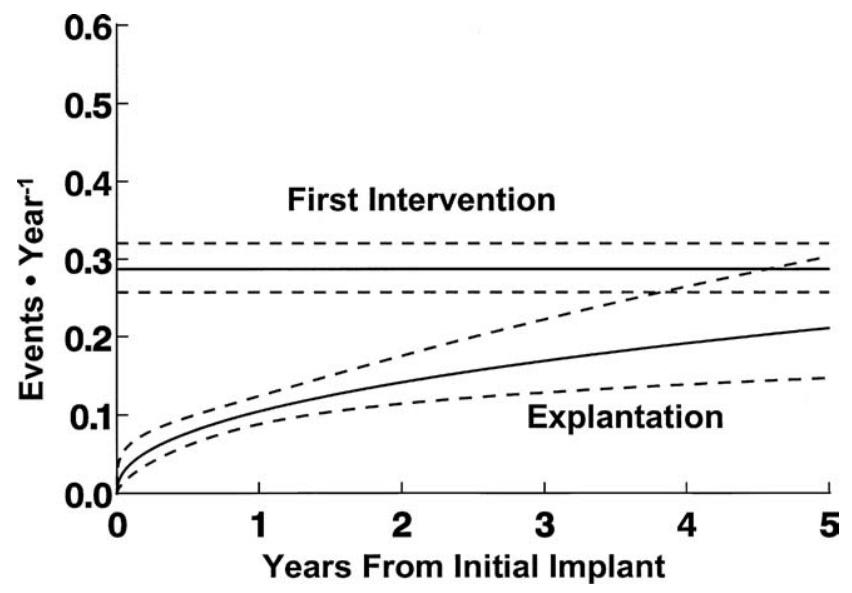

Figure 2. Instantaneous risk (hazard function) of first conduitrelated intervention. There is an ongoing late hazard for conduit explantation ( $n=37$ ) that eventually, at 4 years, exceeds the constant hazard for first conduit-related interventions (including catheter-based events $(n=63)$ and conduit reoperations ( $n=$ 26)). Catheter-based intervention and repair, therefore, are effective at prolonging conduit longevity by blunting the early rise in risk and decreasing the prevalence of explantation within the first year after initial implantation. Solid curves are parametric estimates enclosed within dashed $68 \%$ confidence limits.

PC obstruction in 22 patients, regurgitation in 8, and pseudoaneurysm in 2 patients. Five patients underwent explantation as an incidental procedure. Prevalence of PC explantation was $7 \%(70 \%$ CIs: $6-8 \%)$ and $30 \%(70 \%$ CIs: $25-34 \%$ ) at 1 and 3 years, respectively (Figure E2). The risk of PC explantation was characterized by an early-rising risk, suggesting that catheter-based intervention and PC repair are effective at prolonging PC longevity by blunting this early risk (Figure 2).

Determinants of Conduit-related Initial Interventions Incremental risk factors associated with an increased risk of first PC-related intervention included the presence of major aortopulmonary collateral arteries (MAPCAs), right pulmonary artery stenosis, smaller initial PC Z-score, younger age at initial PC insertion, and the use of a proximal noncircumferential autologous pericardial extension (Table E2). The relationship between initial PC Z-score and intervention was nonlinear. Estimated risk-adjusted prevalence of first PC intervention at 2 years after implant is $100 \%$ when the initial PC Z-score is less than -1 , with no further reduction in risk at initial $\mathrm{PC} Z$-score greater than +1 (Figure 3, A). Two specific solutions to the multivariable equation for first intervention show the disparate outcome for a child in whom a proximal noncircumferential extension with autologous pericardium was used compared with the outcome for a patient in whom either no proximal

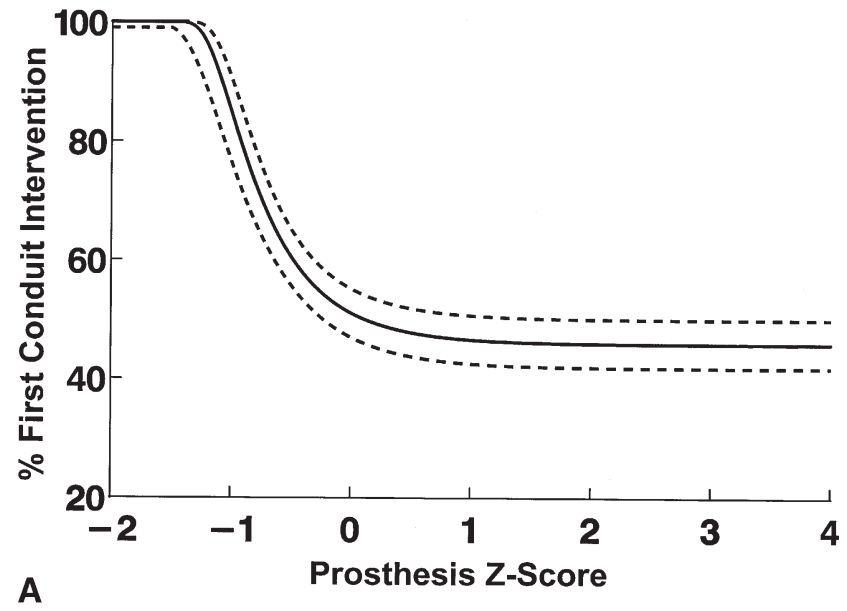

A) Proximal noncircumferential extension with

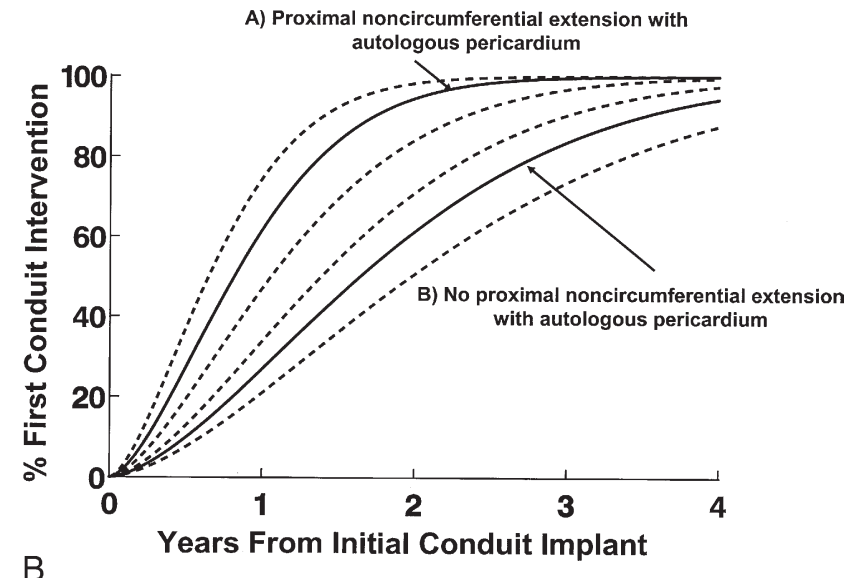

B

Figure 3. A, Risk-adjusted nomogram shows the relationship between the initial pulmonary conduit Z-score and the prevalence of first conduit-related intervention at $\mathbf{2}$ years from initial conduit implantation. The relationship is nonlinear, whereupon intervention is universal for children whose initial PC Z-score was less than -1.5 , with a rapidly decreasing risk as the Z-score approaches +1 . However, there is no further incremental reduction in risk at conduit Z-scores greater than +1 . Solid lines are continuous parametric point estimates enclosed by dashed confidence limits equivalent to 1 standard error (68\%). B, Riskadjusted estimates of first conduit intervention for 2 different patients on the basis of whether or not a proximal noncircumferential extension with autologous pericardium was used. In $A$, the multivariable equation for first conduit intervention has been solved for a patient with MAPCAs who undergoes initial conduit placement with the use of an ideally sized conduit (Z-score = +2 ) at age 2 months with the use of a pericardial extension. In B, the multivariable equation has been solved for a patient with the same characteristics and initial conduit Z-score without proximal extension or use of material other than autologous pericardium. For patient $A$, conduit reintervention is $60 \%$ at 1 year after initial conduit insertion. In contrast, the prevalence of conduit reintervention for patient B is only $25 \%$ at 1 year after initial conduit implant. Solid lines are parametric point estimates enclosed by dashed confidence limits equivalent to 1 standard error (68\%). 


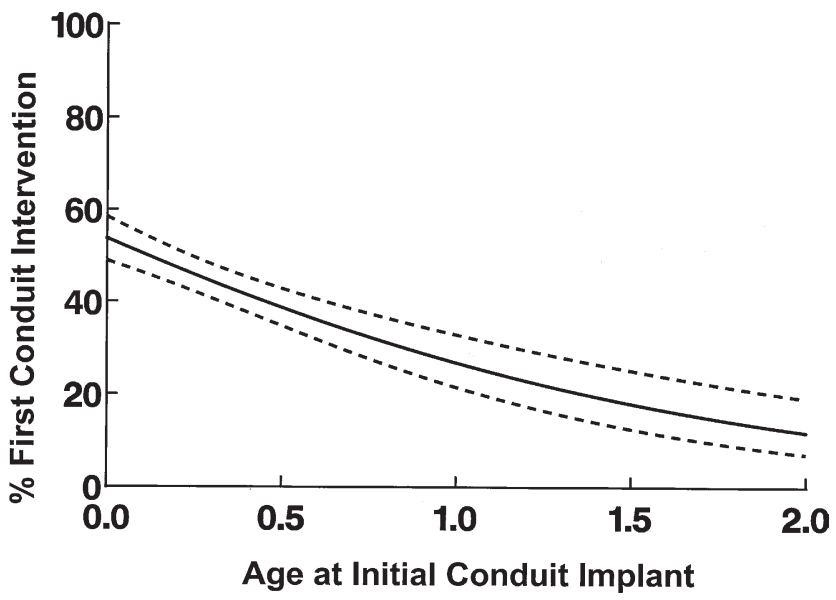

Figure 4. Risk-adjusted nomogram shows the relationship between the initial patient age and first conduit-related intervention at 2 years after initial implant. Conduit interventions occur earlier in younger patients, especially in those less than age $\mathbf{1}$ year at the time of initial conduit insertion. Solid lines are parametric point estimates enclosed by dashed confidence limits equivalent to 1 standard error $(68 \%)$.

extension was used or in whom the extension was constructed with material other than autologous pericardium (Figure 3, B).

The relationship between age at initial PC placement and first PC-related intervention was also nonlinear. PC intervention occurred earlier in the youngest patients, with a rapidly decreasing risk in children greater than 1 year of age at initial PC placement (Figure 4, A). Two specific solutions to the multivariable equation for first intervention show the disparate outcome for a patient with favorable characteristics undergoing initial PC implantation at age 2 years compared with the outcome for a patient with more favorable characteristics undergoing PC implantation as a neonate (Figure E3).

Risk of first PC intervention was independent of PC type (Figure E4), PC manufacturer, preparation technique (including decellularization), ABO blood-group mismatch, donor age or gender match, warm and cold ischemic times, and duration of cryopreservation.

\section{Determinants of Conduit Explantation}

Incremental risk factors associated with an increased risk of PC explantation were smaller Z-value for the right pulmonary artery, bilateral pulmonary artery stenoses (surrogated by bilateral pulmonary arterioplasties concomitant with initial PC placement), and smaller initial PC Z-score (Table E2). PC explantation was also independent of PC type (Figure E5).

\section{Longitudinal Assessment of Conduit Function}

Serial echocardiographic measurements $(\mathrm{n}=729)$ were collected in 224 patients at a median interval of 2.6 months (ranging to 3.6 years) after initial PC insertion. The median number of echocardiograms per patient was 3 (range 1-13).

Progression of PC peak instantaneous gradient. Peak Doppler gradients $(\mathrm{n}=512)$ progressed nonlinearly in all patients over time $(P<.001$; Figure $5, A)$. Gradient progression was more rapid in children having aortic allografts than in those with all other conduit types $(P=.01$; Figure 5, B). Peak gradients were higher at all time points in those with proximal noncircumferential autologous pericardial extension $(P=.007$, Table E3). The relationship between initial PC Z-score and gradient progression was complex, whereupon children with initial PC Z-score less than +1 or greater than +3 had more rapid progression than those with intermediate initial PC size (Figure 5, C).

Progression of $P C$ regurgitation. Similarly, subjective PC regurgitation grade $(\mathrm{n}=552)$ progressed nonlinearly in all patients $(P<.001$; Figure $6, A)$. Factors associated with more severe $\mathrm{PC}$ regurgitation across time included younger age at initial PC implant $(P<.001)$ and larger initial PC $\mathrm{Z}$-score $(P=.004$; Table E3). Using quartiles of the initial PC Z-score, we found that the upper $25 \%$, corresponding to a Z-score greater than +3 , was associated with more severe regurgitation than was the lower $75 \%$ (Figure $6, B$ ). A significant time interaction existed for bovine jugular venous valved conduit type (JVV), whereby children with JVVs, despite having a higher initial grade of regurgitation, had a lower probability of subsequent progression to a more severe regurgitation grade than did children with other PC types (Figure E6). There was also a trend toward more severe regurgitation in children having aortic allografts $(P$ $=.053$ ), although statistical significance was not reached.

\section{Discussion}

This study is the first prospective, multi-institutional comparison of PC durability and function as delineated by echocardiography among currently available PC types in infants and young children. We have shown that PC intervention and explantation occur commonly and that echocardiographic progression of stenosis and regurgitation are universal when PC insertion is performed in those less than 2 years of age. Our results show that younger age at initial PC implant, the presence of pulmonary artery arborization abnormalities, and an initial PC Z-score less than +1 increase the risk of PC-related intervention and explantation. We have determined, using our longitudinal echocardiographic data, that an initial PC Z-score between +1 and +3 minimizes both peak gradient and regurgitation progression. Finally, although PC-related intervention was independent of PC type, aortic allografts had more rapid peak gradient 
progression and also tended toward more severe grade of regurgitation than did other $\mathrm{PC}$ types.

Previous studies have demonstrated the accelerated risk of deterioration and replacement of valved conduits from a ventricle to the pulmonary arteries in neonates and small
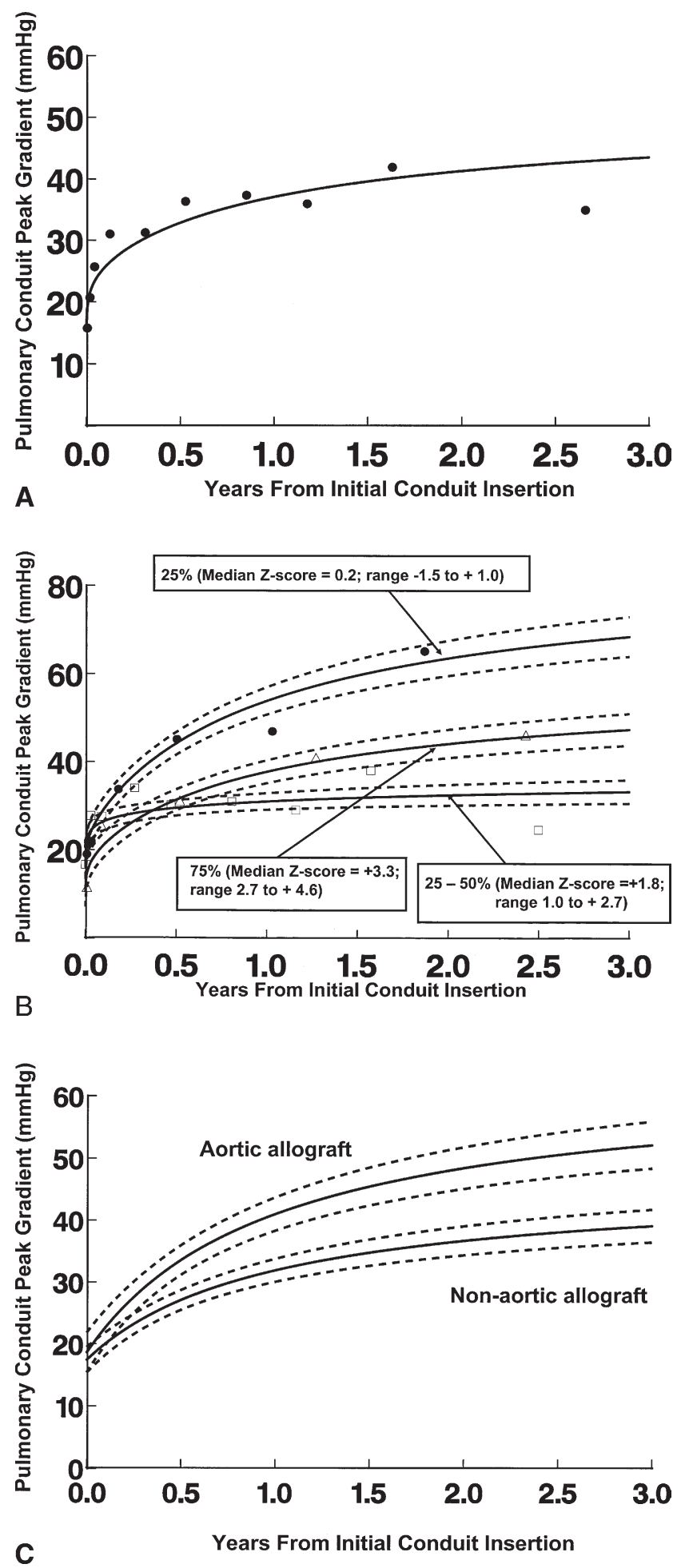

children. ${ }^{1-3}$ These studies have largely concentrated on those factors associated with surgical reintervention and conduit explantation, with relatively little information on the prevalence of PC-sparing interventions and their role in the extension of the functional life of these valved conduits. Our study demonstrates that approximately $40 \%$ of children having initial PC insertion at age less than 2 years will undergo an intervention within 2 years after PC implantation, with most of these interventions initially catheter-based. The increased prevalence of percutaneous intervention after valved conduit implantation in our study compared with others ${ }^{12}$ is likely related to lower thresholds for catheter-based intervention in 2006 compared with a prior era, as well as the complex pulmonary arterial anatomy of children in our series. Importantly, we found that catheter-based intervention and conduit repair are effective at prolonging $\mathrm{PC}$ durability by blunting the initial early risk associated with PC explantation. Although a potentially lower threshold for catheter-based intervention than for PC replacement makes the true measure of PC durability and need for reoperation difficult to ascertain, certainly, if most children had undergone PC explantation rather that catheterbased intervention, the prevalence of reoperation would have been much higher and reoperation would have occurred much earlier. This supports the current initial use of catheter-based interventions for PC-related obstruction and

Figure 5. A, Echocardiographic Doppler peak gradient across the right ventricle-pulmonary artery conduit progressed nonlinearly in all patients over time $(P<.001)$. Gradient progression was rapid in the initial year after conduit implant and tapered thereafter. Closed circles represent the mean value for the peak gradient for deciles of time; solid lines represent continuous point estimates from the mixed linear regression model. B, Estimated echocardiographic Doppler peak gradient across the right ventricle-pulmonary artery conduit progression stratified by initial conduit Z-score. Quartiles of the initial conduit Z-score were generated. For clarity, the middle 2 quartiles were combined into a single intermediate group. Peak gradient progressed more rapidly in those patients within the lower 25th and upper 75th percentiles for initial conduit Z-score, indicating that oversizing conduits beyond a Z-score of +3 may accelerate gradient progression. Geometric symbols represent the mean peak gradients within each Z-score group per decile of time; solid lines are continuous parametric estimates enclosed by dashed $70 \%$ confidence limits. C, Estimated echocardiographic Doppler peak gradient across the pulmonary conduit after initial conduit insertion stratified by conduit type (aortic allograft vs non-aortic allograft) shows that patients having aortic allografts had more rapid gradient progression $(P<.001)$ than did patients with all other conduit types after adjustment for other significant predictors. Solid lines are continuous point estimates enclosed by dashed $70 \%$ confidence limits. 

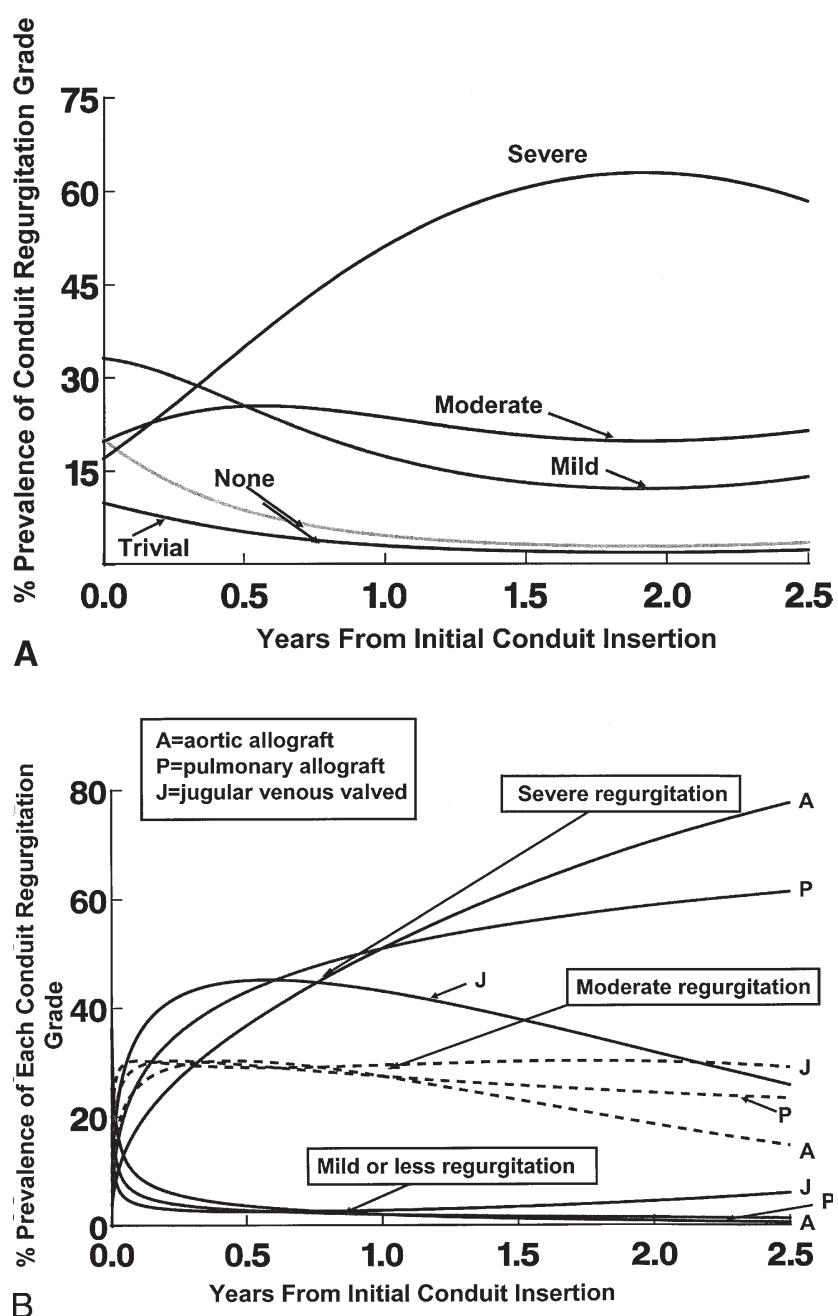

Figure 6. A, The prevalence of more severe conduit regurgitation, by subjective grade as determined by echocardiography, increased nonlinearly over time. As time elapsed, the proportion of patients having severe regurgitation increases dramatically, with proportionally fewer patients remaining in lower ordered grades. Solid lines are continuous point estimates and show the proportion or each individual regurgitation grade over time. B, Risk-adjusted estimates of the proportion of patients that will exist in each subjective grade of regurgitation over time stratified by the 3 major conduit types. The graph demonstrates the increased prevalence of both moderate and severe regurgitation as more time elapses from initial conduit placement. The 3 solid lines at the top represent severe regurgitation; the 3 middle dashed lines represent moderate regurgitation, and the bottom 3 solid lines represent mild or less regurgitation. Patients with JVV conduits had a significantly lower probability of being in a higher ordered grade of regurgitation than did others, and children having initial aortic allografts tended to have a higher probability of having more severe regurgitation. that these interventions appear to delay the need for PC explantation. ${ }^{13-15}$

Despite the relatively short follow-up period, conduit explantation was undertaken in $20 \%$ of our patients up to 2 years from initial implant. We demonstrated that younger age at initial PC placement and initial PC Z-score less than +1 are associated with an increased risk of first PC intervention, emphasizing the importance of appropriately sizing the PCs to maximize durability. Although many studies have shown that undersized PCs predispose to early PC failure, ${ }^{16-18}$ Wells, ${ }^{7}$ Karamlou, ${ }^{19}$ and their colleagues, reported that placement of oversized PCs does not improve durability even in young infants at high risk for somatic outgrowth. Oversizing heterotopically placed PCs in certain diagnostic subgroups (eg, L-transposition of the great arteries with pulmonary atresia) may further increase the risk of sternal compression and reduce PC durability. However, we did not find that either of these diagnostic subgroups was associated with adverse outcome, and therefore a recommendation that PCs be further downsized in the presence of these diagnoses would be speculative. Our longitudinal echocardiographic analysis of PC function allowed further elucidation of an ideal initial PC Z-score. We showed that an initial PC Z-score between +1 and +3 minimizes both peak gradient and regurgitation progression. On the basis of this study, we recommend that a valve with a Z-score between +1 and +3 be used in children undergoing PC insertion at age less than 2 years.

Additionally, we found the presence of MAPCAs and right pulmonary artery stenosis to be risk factors for PC-related intervention. The influence of pulmonary artery arborization abnormalities underscores the role that increased pulmonary artery pressure and resistance may play in early PC deterioration. Further, any technical or anatomic situation resulting in obstruction or high pressure within the PC could potentially lead to earlier explantation. In support of this contention, the series by Heinemann and colleagues ${ }^{20}$ found that even a mild postoperative right ventricle-pulmonary pressure gradient was a risk factor for PC replacement within 2 years after repair of truncus arteriosus.

Our finding that autologous pericardial noncircumferential extensions contribute both to the need for PC intervention and to more rapid peak gradient progression is puzzling and contrasts with the findings of others who have observed that expanded polytetraflouroethelyne ${ }^{21}$ and Dacron $^{22}$ extensions confer an increased risk of intervention for relief of PC obstruction.

Importantly, we did not find $\mathrm{PC}$ type to be a risk factor for either first PC intervention or explantation. However, our longitudinal echocardiographic assessment of conduit function demonstrated that aortic allografts had early development of stenosis and tended to have earlier progression of PC regurgitation after adjustment for other factors. Early 
deterioration and failure of aortic allografts has been reported by others, ${ }^{1,13,23,24}$ but it has previously been difficult to determine whether this was due to an inherent disadvantage of the aortic allograft or due to other confounding patient-related factors. Conversely, JVVs had less progression of regurgitation than did other PC types despite higher initial regurgitation grade. Early favorable hemodynamics were similarly reported by Carrel, ${ }^{24}$ Breymann, ${ }^{25}$ and their colleagues, with the use of JVVs. Potential reasons for improved hemodynamic performance may be related to obviation of the need for proximal extension hoods and their associated additional suture lines with JVVs, or potentially more favorable handling characteristics compared with other PC types. The ability to tailor JVVs also may facilitate more distal position of the valve, thereby avoiding compression by the sternum. The wider availability of JVVs makes their use in infants even more attractive owing to the relative scarcity of small allograft valves. Longer-term follow-up is needed to determine whether early differences in PC function as delineated by echocardiography will translate into improved PC durability.

The finding that porcine heterografts were not associated with decreased PC durability in these young children was unexpected. Our experience with porcine xenografts was quite favorable, but limited with only 5 patients, precluding recommendations based on our results. Porcine valved Dacron conduits have been shown by others to require earlier intervention than allografts. ${ }^{17,26}$ In contrast, Dearani and colleagues ${ }^{27}$ reported that porcine heterografts and porcinevalved Dacron conduits were more durable than allografts. Newer technology fixation techniques applied to aortic bioprostheses may allow better porcine valved conduits in smaller sizes in the future.

\section{Study Limitations}

There are several limitations to this large, multi-institutional study. We acknowledge that it is nearly impossible to examine carefully different valve types and the risk factors for PC failure outside the scope of a randomized trial. Techniques of PC implantation and criteria for intervention and replacement were not standardized and therefore are automatically variable. Absence of protocolized echocardiographic review is another important limitation. Valve types were not uniform in number, with allografts predominating and JVVs and decellularized allografts less commonly and more recently used. Follow-up in this series is relatively short, even though a large number of events did occur during the time period examined.

\section{Conclusions}

Selection of a valved conduit with a Z-score between +1 to +3 at initial implantation allows optimal PC durability in this difficult-to-treat group of infants and young children.
Initial intervention with catheter-based techniques and surgical repair are advantageous in reducing PC failure. Aortic allografts have inferior PC function on early echocardiographic examination, but longer follow-up is needed to determine whether this will translate into decreased PC longevity. ${ }^{28}$

We are grateful to the members of the Pulmonary Conduit Working Group: Christo I. Tchervenkov, MD, Montreal, Quebec, Canada; David M. Overman, MD, Minneapolis, Minn; Thomas Yeh, Jr, MD, PhD, Dallas, Tex; Jeffrey P. Jacobs, MD, St. Petersburg, Fla; Linda M. Lambert, RN, Salt Lake City, Utah. These individuals assisted in data verification, analysis, and manuscript preparation. We are grateful for the assistance of personnel from the CHSS Data Center, particularly Geraldine Cullen-Dean, Sally Cai, Haddas Grosbein, and Candice Cumberbach, for coordinating the collection and management of these data. We thank all the members of the CHSS and their pediatric cardiology colleagues for their contributions to this study. Participating institutions are listed in Table E4.

\section{References}

1. Chan KC, Fyfe DA, McKay CA, Sade RM, Crawford FA. Right ventricular outflow reconstruction with cryopreserved homografts in pediatric patients: intermediate-term follow-up with serial echocardiographic assessment. J Am Coll Cardiol. 1994;24:483-9.

2. Clarke DR, Bishop DA. Allograft degeneration in pulmonary valve allograft recipients. Eur J Cardiothorac Surg. 1993;7:365-70.

3. Clarke DR, Campbell DN, Hayward AR, Bishop DA. Degeneration of aortic allografts in young recipients. J Thorac Cardiovasc Surg. 1993; 105:934-42.

4. Hawkins JA, Hillman ND, Lambert LM, Jones J, Di Russo GB, Profaizer $\mathrm{T}$, et al. Immunogenicity of decellularized cryopreserved allografts in pediatric cardiac surgery: comparison with standard cryopreserved allografts. J Thorac Cardiovasc Surg. 2003;126:247-52; discussion 252-3.

5. Baskett RJ, Nanton MA, Warren AE, Ross DB. Human leukocyte antigen-DR and ABO mismatch are associated with accelerated homograft valve failure in children: implications for therapeutic interventions. J Thorac Cardiovasc Surg. 2003;126:232-9.

6. Stark J, Bull C, Stajevic M, Jothi M, Elliott M, de Leval M. Fate of subpulmonary homograft conduits: determinants of late homograft failure. J Thorac Cardiovasc Surg. 1998;115:506-14; discussion 514-6.

7. Wells WJ, Arroyo H Jr, Bremner RM, Wood J, Starnes VA. Homograft conduit failure in infants is not due to somatic outgrowth. J Thorac Cardiovasc Surg. 2002;124:88-96.

8. Daubeney PEF, Blackstone EH, Weintraub RG, Slavik Z, Scanlon J, Webber SA. Relationship of the dimension of cardiac structures to body size: an echocardiographic study in normal infants and children. Cardiol Young. 1999;9:402-10.

9. Kirklin JW, Blackstone EH, Jonas RA, Kouchoukos NT. In: Kirklin JW, Barratt-Boyes BG, editors. Cardiac surgery, 3rd ed. Edinburgh: Churchill Livingstone; 2004. Chapter 1, appendix 1G, p. 50.

10. Blackstone EH, Naftel DC, Turner ME Jr. The decomposition of time-varying hazard into phases, each incorporating a separate stream of concomitant information. J Am Stat Assoc. 1986;81:615-24.

11. Blackstone EH. Breaking down barriers: helpful breakthrough statistical methods you need to understand better. J Thorac Cardiovasc Surg. 2001;122:430-9.

12. Perron J, Moran AM, Gavreau K, del Nido PJ, Jonas RA. Valved homograft conduit repair of the right heart in early infancy. Ann Thorac Surg. 1999;68:542-8.

13. Forbess JM, Shah AS, St Louis JD, Jaggers JJ, Ungerleider RM. Cryopreserved homografts in the pulmonary position: determinants of durability. Ann Thorac Surg. 2001;71:54-9; discussion 59-60.

14. Powell AJ, Lock JE, Keane JF, Perry SB. Prolongation of RV-PA conduit life span by percutaneous stent implantation. Intermediateterm results. Circulation. 1995;92:3282-8. 
15. Williams JM, de Leeuw M, Black MD, Freedom RM, Williams WG, McCrindle BW. Factors associated with outcomes of persistent truncus arteriosus. J Am Coll Cardiol. 1999;34:545-53.

16. Sinzobahamvya N, Wetter J, Blaschczok HC, Cho MY, Brecher AM, Urban AE. The fate of small-diameter homografts in the pulmonary position. Ann Thorac Surg. 2001;72:2070-6.

17. Caldarone CA, McCrindle BW, Van Arsdell GS, Coles JG, Webb G, Freedom RM, et al. Independent factors associated with longevity of prosthetic pulmonary valves and valved conduits. $J$ Thorac Cardiovasc Surg. 2000;120:1022-31.

18. Tweddell JS, Pelech AN, Frommelt PC, Mussatto KA, Wyman JD, Fedderly RT, et al. Factors affecting longevity of homograft valves used for right ventricular outflow tract reconstruction in congenital heart disease. Circulation. 2000;102(suppl III)III130-5.

19. Karamlou T, Ungerleider RM, Alsoufi B, Burch G, Silberbach M, Reller M, et al. Oversizing pulmonary homograft conduits does not significantly decrease allograft failure in children. Eur J Cardiothorac Surg. 2005;27:548-53.

20. Heinemann MK, Hanley FL, Fenton KN, Jonas RA, Mayer JE, Castaneda AR. Fate of small homograft conduits after early repair of truncus arteriosus. Ann Thorac Surg. 1993;55:1409-11.

21. Tatebe S, Nagakura S, Boyle EM Jr, Duncan BW. Right ventricle to pulmonary artery reconstruction using a valved homograft. Circ J. 2003;67:906-12.

22. Kobayashi J, Backer CL, Zales VR, Crawford SE, Muster AJ, Mavroudis C. Failure of the Hemashield extension in right ventricle-topulmonary artery conduits. Ann Thorac Surg. 1993;56:277-81.

23. Bando K, Danielson GK, Schaff HV, Mair DD, Julsrud PR, Puga FJ. Outcome of pulmonary and aortic homografts for right ventricular outflow tract reconstruction. J Thorac Cardiovasc Surg. 1995;109: 509-17.

24. Niyawa K, Knott-Craig CJ, Lane MM, Overholt ED, Elkins RC. Cryopreserved homograft valves in the pulmonary position: riskanalysis for intermediate-term failure. $J$ Thorac Cardiovasc Surg. 1999;117:141-6.

25. Carrel T, Berdat P, Pavlovic M, Pfammatter JP. The bovine jugular vein: a totally integrated valved conduit to repair the right ventricular outflow. J Heart Valve Dis. 2002;11:552-6.

26. Breymann T, Thies WR, Boethig D, Goerg R, Blanz U, Koerfer R. Bovine valved venous xenografts for RVOT reconstruction. Eur J Cardiothorac Surg. 2002;21:703-10.

27. Homann M, Haehnel JC, Mendler N, Paek SU, Holper K, Meisner H, et al. Reconstruction of the RVOT with valved biological conduits: 25 years experience with allografts and xenografts. Eur J Cardiothorac Surg. 2000;17:624-30.

28. Dearani JA, Danielson GK, Puga FJ, Schaff HV, Warnes CW, Driscoll DJ, et al. Late follow-up of 1095 patients undergoing operation for complex congenital heart disease utilizing pulmonary ventricle to pulmonary artery conduits. Ann Thorac Surg. 2003;75:399-411.

\section{Discussion}

Dr Joseph A. Dearani (Rochester, Minn). I have no disclosures.

I would like to congratulate Dr Karamlou, the coauthors, and the participating members of the CHSS for this outstanding presentation and important contribution on the results of extracardiac conduits in infants and young children. This group of patients continues to present difficult challenges to interventional cardiologists and surgeons, since reinterventions are eventually required in all patients. The manuscript is well written and the analysis is detailed and comprehensive in the usual Blackstone fashion.

It has been 42 years since Dr Kirklin placed the first conduit during repair of pulmonary atresia in a 6-year-old child. Advances in neonatal intensive care unit care and advances in neonatal surgical techniques, including those that use a conduit, have resulted in successful repair of very complex lesions during infancy.

Importantly, this study is the first prospective, multi-institutional comparison of PC durability and function as delineated by echo- cardiography among currently available PCs in infants and young children. Conduits used included pulmonary and aortic homografts and bovine JVV grafts. The authors' main conclusion was that conduit durability and hemodynamic function were improved by using larger conduits, that is, conduits upsized with Z-scores between +1 and +3 .

Another critically important finding noted in this review was that the durability of the bovine JVV graft was comparable with that of the homograft, which has been the conduit of choice in infants and small children. Given the limited availability of homografts in small sizes, this issue is of practical importance to the surgeon when dealing with the infant, since the handling characteristics of the bovine graft are quite favorable and there is greater availability in smaller sizes.

Although these children were followed prospectively, it is important to note that the study was nonrandomized. The authors have identified a poorer outcome in aortic homografts and a trend of a greater degree of regurgitation in aortic homografts. We and others have demonstrated that aortic homografts are more likely to have minimal regurgitation early after operation than are pulmonary homografts. As such, in this nonrandomized study, surgeons may have preferred the aortic homograft when the anticipated pulmonary artery and right ventricular pressures were going to be elevated at the end of the operation.

My first series of questions is on this topic. Was there a correlation between conduit type and durability while factoring right ventricular pressure at the end of operation? That is, do you think there was a selection bias and that the greater degree of regurgitation seen in the aortic homografts was due to these factors as opposed to the type of conduit?

Dr Karamlou. I think that the answer to your question is no. Although our catheter data were somewhat opportunistic in that we usually retrieved catheterization data according to interventions, I can say that we did look at right ventricular pressures, we did look at mean pulmonary artery pressures, and there was no significant difference among conduit types regarding those hemodynamic measures. Although we cannot say for certain, because the study was nonrandomized and therefore the indications for specific conduit types were variable, I think that, as best as we could have done in the nonrandomized study, we did look at hemodynamics and it was not an important variable that affected either the selection of each conduit type nor the outcome.

Dr Dearani. With that in mind, which conduit would you use, the bovine JVV graft, if you expect the right ventricular pressure to be elevated at the end of the operation?

Dr Karamlou. On the basis of the data that we have shown today, there probably is no benefit to using an aortic allograft even in those patients. As you noted from the risk-adjusted model, pulmonary artery arborization anomalies did fall out as significant predictors; therefore, after adjusting for these particular unfavorable morphologic characteristics, still there was no impact of conduit type. So I'd have to say yes.

Dr Dearani. We have also learned from the surgical literature that right ventricle-pulmonary artery conduits placed in the orthotopic position, for example, in patients with tetralogy-like anatomy, are more durable because of a more natural anatomic position, compared with conduits placed in the heterotopic position, for 
example, transposition and truncus. This issue becomes important when upsizing the conduit.

Heterotopic conduit placement is more susceptible to compression with sternal closure. Patients most at risk would be those with transposition or truncus. Was chest closure a problem in any of these patients? What are your recommendations about not oversizing the conduit too much when these particular diagnoses are being factored into the equation?

Dr Karamlou. In a large proportion of infants, the chest was not closed after the initial conduit placement. We did look at what we termed non-conduit-related procedures as a risk factor, and this did not fall out as a risk factor for conduit durability, although we did not look at morbidity or survival because those were not end points examined in the study. So I cannot specifically answer your question regarding sternal closure as a potential determinant of morbidity. However, I still think it is very important not to oversize the conduit. This is especially crucial, for instance, in corrected transposition or other morphologic types, when the conduit may be either in a very adverse position or directly underneath the sternum. I think especially in those cases, you want to avoid oversizing because that can lead to sternal compression, kinking, and perhaps an accelerated risk of stenosis.

Dr Dearani. Finally, it was interesting that a noncircumferential pericardial hood was a risk factor for reintervention. In our experience, a nonpericardial hood was more problematic. However, when a pericardial hood was used, it did not matter whether it was circumferential or noncircumferential, the obstruction almost always occurred at the valvular level of these homografts. Could you comment on this?

Dr Karamlou. We were very surprised by the finding that autologous pericardium was a risk factor both for conduit intervention and for an accelerated risk of gradient progression. We are aware of your results showing exactly the opposite.

I can say that it is potentially confounded by the fact that this fell out as a risk factor against all other things, including not placing a proximal extension of any kind. It could very well be that what we are really detecting is that it is more favorable to avoid any kind of proximal extension with its attendant additional suture lines, and that could be the reason that we are seeing this as a risk factor.

Dr Vaughn A. Starnes (Los Angeles, Calif). I am having a real problem with the idea that this autologous extension is a risk factor. What I think I understand you to say is that this is a group of heterotopically placed conduits. Did you analyze that as a separate multivariate analysis? When you look at pericardial extension versus heterotopic placement, does it still fall out as a risk factor?

Dr Karamlou. We did look at orthotopicity, and actually there is really a spectrum of orthotopicity. We looked at just the Ross procedures as being the purest form of orthotopic placement versus those with maybe less orthotopicity being the 10 absent valve patients, and none of those things came out as favorable factors that obviated the need for conduit intervention.

All I can say is that we are surprised at this and it probably requires further study. Regardless of all of those other factors, it still was a very strong determinant of both of those end points.
Dr Scott M. Bradley (Charleston, SC). Were proximal hoods made of other material used frequently enough that you could say that those other materials were not risk factors?

Dr Karamlou. Yes, with the exception probably of xenograft pericardium, all of the different types, including synthetic material, aortic pulmonary homograft, and what we termed unspecified homograft whose composition could not be precisely documented, I think that those were populated enough that we could look at those types of things as risk factors.

Again, it is difficult to sort out. Is it that the autologous pericardium was used in cases where the conduit was heterotopic? Was it that larger initial Z-scores are confounded with hood placements?

It is sometimes a little bit difficult to ascertain exactly which things are truly related to outcome with this type of multicollinearity.

Dr Antonio F. Corno (Liverpool, United Kingdom). The obstruction of a right ventricle-pulmonary artery conduit can well be due to the fact that the patient is outgrowing the conduit, particularly when you consider patients between 6 and 24 months of age, when there is the most important growth of body surface area and when you can implant a relatively small-sized conduit. But it can also be due to, or can be increased by, technical complications.

Did you try to analyze whether the pressure gradient was all along the conduit, or, in certain cases, was mainly localized at the level of the proximal anastomosis or at the level of the distal anastomosis?

Dr Karamlou. Yes, we did. In fact, all of the members of the working group tried, through adjudication, to determine what was the predominant reason for conduit placement-was it somatic outgrowth, was it valvular, was it diffuse, was it distal? We tried as best as we could, from again. Most of the material can be really looked at objectively through cardiac catheterization data, which we did not have a full composite of over the time period. Again, most of these things were obtained at the time of intervention. As this cohort matures (this study was just initiated in 2002), we hope to accrue more patients and to look at cardiac catheterizations in a more nonbiased way. Potentially we can answer your question more precisely.

Dr John E. Mayer, Jr (Boston, Mass). Having contributed a fair number of these conduits, I'm sure, I guess my concern reflects a little bit of what Dr Dearani was talking about: certainly if there were situations in which we anticipated that the distal pulmonary artery pressures were going to be elevated or there was going to be high impedance or resistance to pulmonary blood flow, I would, by preference, have chosen an aortic homograft as opposed to a pulmonary homograft, for instance. I think there is some clue that that is what is going on because of the impact of this pulmonary artery arborization as being also associated with an earlier failure rate or earlier reintervention.

How it is that you are able to separate out the factor interactions that you have identified through your multiple logistic regression? Second, is there not additional work that might need to be done to make sure that somehow or another these factors are not, in fact, interacting?

Dr Karamlou. Your first question certainly does require further study, and that's why the study is ongoing. We hope that you all will continue to send your patients so that we can answer these important questions. 
It was a comprehensive data set and we did consider all interactions, including those with hemodynamic parameters and specific conduit types. As you are no doubt aware, as you introduce more variables, you run into an overspecified model with a small number of events. That's why we tried to use our longitudinal analysis to get around some of these potential type 2 errors or power-related errors.
From a nonrandomized study with a small number of patients per institution, we cannot reliably control for institutional bias favoring aortic allografts in patients with unfavorable morphology or propensity toward regurgitation. However, if you look at the full model that we fit, pulmonary artery arborization abnormalities were significant predictors of conduit failure while conduit type was not.

Now you can get The Journal of Thoracic and Cardiovascular Surgery online. The Journal online brings you faster delivery time, easy searching of current and back issues, links to PubMed, AATS, WTSA, and other important sites, and more. Visit the Journal online today.

\section{Receive tables of contents by e-mail}

To receive the tables of contents by e-mail, sign up through our Web site at http://journals.elsevierhealth.com/periodicals/ymtc

Choose E-mail Notification

Simply type your e-mail address in the box and click the Subscribe button. You will receive an e-mail to confirm that you have been added to the mailing list.

Note that TOC e-mails will be sent out when a new issue is posted to the Web site. 


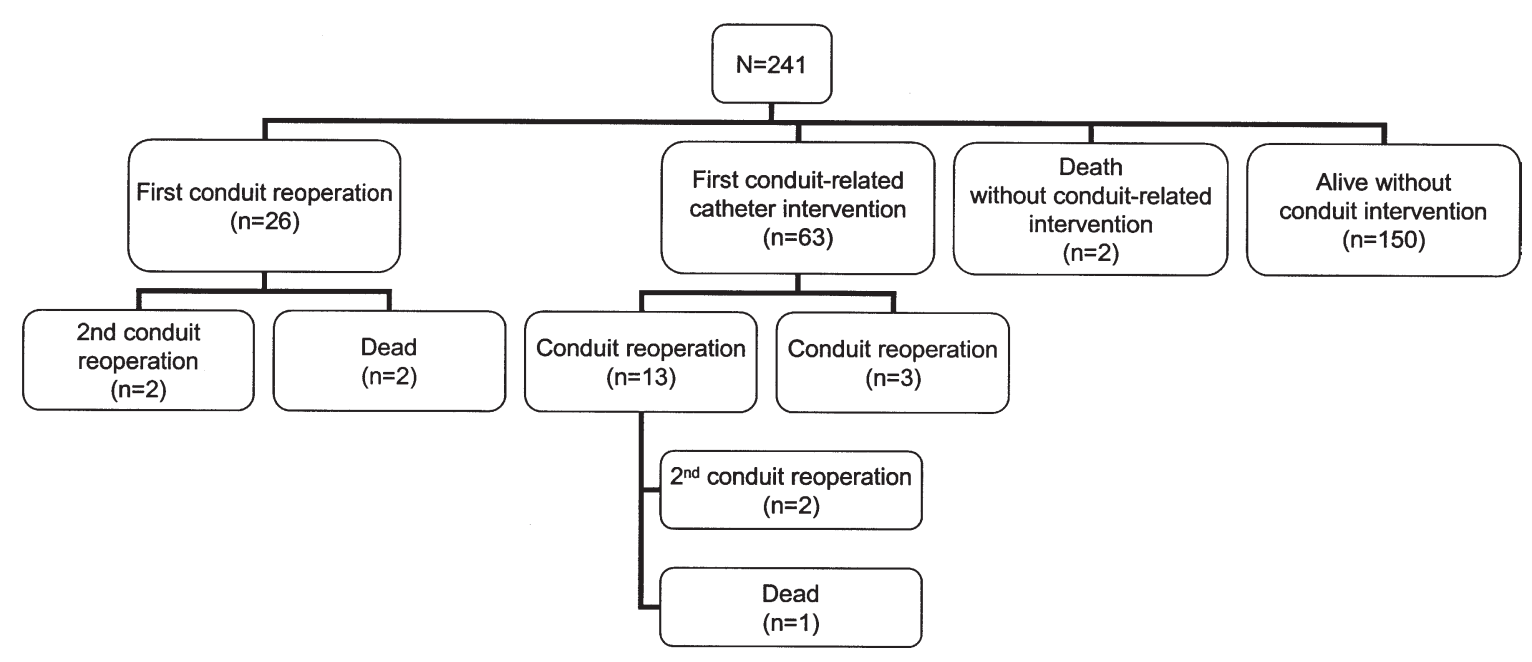

Figure E1. Outcomes of children receiving first valved ventricle-pulmonary artery conduit. Note that there were 4 patients who had a second conduit reoperation (1 repair and 3 replacements). Thus, in total, there were 280 conduits placed in $\mathbf{2 4 1}$ patients during the study period. Five patients have died, and $\mathbf{1 5 0}$ patients currently remain free of any conduit-related intervention after their initial conduit placement. Three patient deaths were related to conduit intervention (although not related to conduit failure per se) and 2 were unrelated, occurring at 6 weeks and 17 months after initial conduit implant. 
TABLE E1. Patient and initial pulmonary conduit characteristics $(n=241)$

\begin{tabular}{|c|c|c|}
\hline Variable & Value & No. missing \\
\hline \multicolumn{3}{|l|}{ Demographic characteristics } \\
\hline Gender (female/male) & 124:117 & 0 \\
\hline Age at conduit implant (median with range) & $1.4 \mathrm{~m}(0-1.95 \mathrm{y})$ & 0 \\
\hline Weight at conduit implant (kg, mean, SD) & $4.8 \pm 2.5$ & 5 \\
\hline Previous surgical procedure & $88(37 \%)$ & 0 \\
\hline \multicolumn{3}{|l|}{ Morphologic characteristics } \\
\hline Primary cardiac diagnosis & & 0 \\
\hline Truncus arteriosus & $88(36 \%)$ & \\
\hline Pulmonary atresia/VSD & $69(29 \%)$ & \\
\hline Aortic valve stenosis/regurgitation & $19(8 \%)$ & \\
\hline TGA with atrioventricular concordance & $16(7 \%)$ & \\
\hline Double-outlet right ventricle & $15(6 \%)$ & \\
\hline ToF with absent pulmonary valve & $14(6 \%)$ & \\
\hline Interrupted aortic arch & $7(2 \%)$ & \\
\hline TGA with atrioventricular discordance & $6(2 \%)$ & \\
\hline ToF & $5(2 \%)$ & \\
\hline Other & $2(<1 \%)$ & \\
\hline Major associated cardiac anomalies & & 0 \\
\hline None & $73(30)$ & \\
\hline Right aortic arch & $48(19 \%)$ & \\
\hline Left ventricular outflow tract obstruction & $30(12 \%)$ & \\
\hline Major aortopulmonary collateral areries & $30(12 \%)$ & \\
\hline Left superior vena cava & $24(10 \%)$ & \\
\hline Atrioventricular valve anomaly & $14(6 \%)$ & \\
\hline Ductal origin of a distal pulmonary artery & $10(4 \%)$ & \\
\hline Coronary artery anomalies & $4(1 \%)$ & \\
\hline RPA stenosis at pre-conduit echocardiogram & $43(25 \%)$ & 69 \\
\hline LPA stenosis at pre-conduit echocardiogram & $42(25 \%)$ & 70 \\
\hline \multicolumn{3}{|l|}{ Initial conduit features } \\
\hline Type of conduit & & 0 \\
\hline Pulmonary allograft & $89(37 \%)$ & \\
\hline Aortic allograft & $71(16 \%)$ & \\
\hline Bovine jugular venous valved & $60(25 \%)$ & \\
\hline Decellularized pulmonary allograft & $9(4 \%)$ & \\
\hline Decellularized aortic allograft & $7(3 \%)$ & \\
\hline Porcine heterograft & $5(2 \%)$ & \\
\hline Size of conduit $(\mathrm{mm}$, mean $\pm \mathrm{SD})$ & $12 \pm 2$ & 0 \\
\hline Z-score of conduit (median and range) & $1.8(-1.5$ to 4.6$)$ & 5 \\
\hline Proximal extension used & $133(55 \%)$ & 0 \\
\hline Noncircumferential & $122(51 \%)$ & \\
\hline Circumferential & $11(5 \%)$ & \\
\hline Proximal extension material & & 0 \\
\hline Allograft & $47(35 \%)$ & \\
\hline PTFE/Dacron & $36(27 \%)$ & \\
\hline Autologous pericardium & $35(26 \%)$ & \\
\hline Xenograft pericardium & $15(11 \%)$ & \\
\hline Concomitant procedures at conduit implant & & 0 \\
\hline LPA arterioplasty & $35(15 \%)$ & \\
\hline RPA arterioplasty & $25(10 \%)$ & \\
\hline Bilateral pulmonary artery arterioplasty & $16(7 \%)$ & \\
\hline Unifocalization & $29(12 \%)$ & \\
\hline ASD fenestration or intentional incomplete closure & $80(33 \%)$ & \\
\hline Konno aortoventriculoplasty & $14(6 \%)$ & \\
\hline Delayed sternal closure after initial conduit implantation & $75(31 \%)$ & 0 \\
\hline
\end{tabular}


TABLE E1. Continued

\begin{tabular}{lrr}
\hline Variable & Value & \\
\hline Factors specific for cryopreserved allografts & & No. missing \\
Warm ischemic time (h, median with range) & $11.2(0.01-49)$ & 42 \\
Total cryopreservation period (y, median with range) & $0.74(0.09-4.2)$ & 35 \\
ABO-blood group incompatible & $39(60 \%)$ & 111 \\
Gender mismatch & $8(46 \%)$ & 0
\end{tabular}

$n$, Number; $m$, months; $y$, years; $k g$, kilograms; $S D$, standard deviation; $m m$, millimeters; $h$, hours; TGA, transposition of the great arteries; $T o F$, tetralogy of Fallot; $A S D$, atrial septal defect; $V S D$, ventricular septal defect; $L P A$, left pulmonary artery; RPA, right pulmonary artery; $P T F E$, polytetrafluoroethylene.

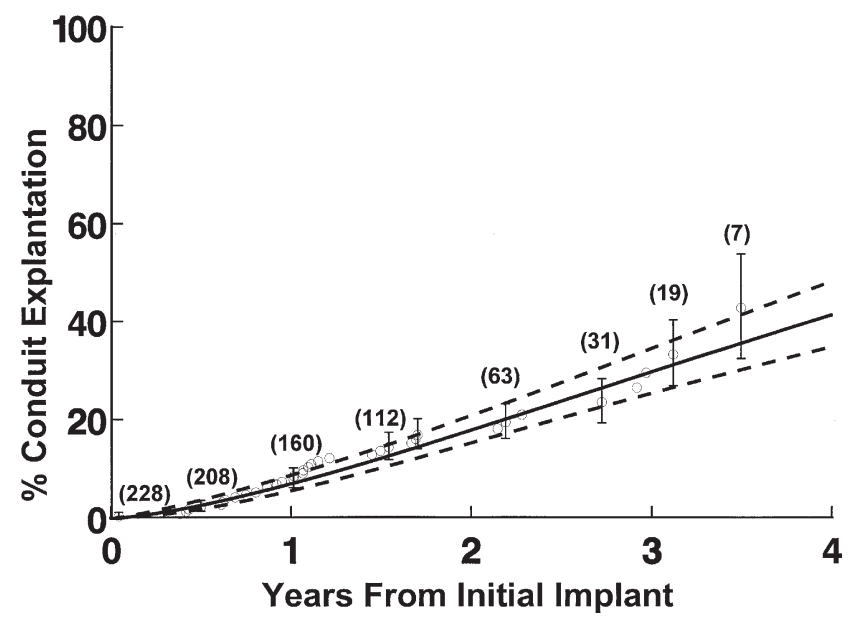

Figure E2. Conduit explantation. Each symbol represents an explantation; vertical lines are asymmetric confidence limits (CLs) equivalent to 1 standard error (68\%); numbers in parentheses are children remaining at risk; solid lines are parametric estimates enclosed in dashed $68 \%$ CLs.

TABLE E2. Incremental risk factors for first conduit-related intervention and explantation

\begin{tabular}{|c|c|c|c|}
\hline Variable & Parameter estimate $( \pm \mathrm{SE})$ & $P$ value & Reliability* (\%) \\
\hline \multicolumn{4}{|l|}{ 1. For first conduit-related intervention } \\
\hline Younger age at initial PC implantation (per 1 year)† & $0.49 \pm 0.20$ & $<.001$ & $77 \%$ \\
\hline Smaller initial PC Z-score $\ddagger$ (per 1 unit) & $0.15 \pm 0.03$ & $<.001$ & $83 \%$ \\
\hline RPA stenosis documented on echocardiogram before PC insertion & $0.94 \pm 0.30$ & .002 & $64 \%$ \\
\hline MAPCAS & $1.08 \pm 0.29$ & $<.001$ & $57 \%$ \\
\hline Use of noncircumferential proximal extension with autologous pericardium & $1.12 \pm 0.30$ & $<.001$ & $81 \%$ \\
\hline \multicolumn{4}{|l|}{ 2. For conduit explantation } \\
\hline Smaller initial PC Z-scoreł (per 1 unit) & $0.32 \pm 0.12$ & .009 & $78 \%$ \\
\hline Smaller RPA Z-score documented on echocardiogram before PC insertion§ & $0.001 \pm 0.003$ & .008 & $69 \%$ \\
\hline Bilateral PA arterioplasty at time of initial PC implant & $1.38 \pm 0.45$ & .002 & $64 \%$ \\
\hline
\end{tabular}

$S E$, Standard error; $P C$, pulmonary conduit; $R P A$, right pulmonary artery; $M A P C A s$, major aortopulmonary collateral arteries; $P A$, pulmonary artery. *Percent $(\%)$ refers to the reliability determined by bootstrap bagging $(1000 \times$ dataset resampling) method. $\uparrow$ After square transformation. $\ddagger$ Complex polynomial term consisting of the inverse of the exponentiated term followed by square transformation. §After inverse transformation. 


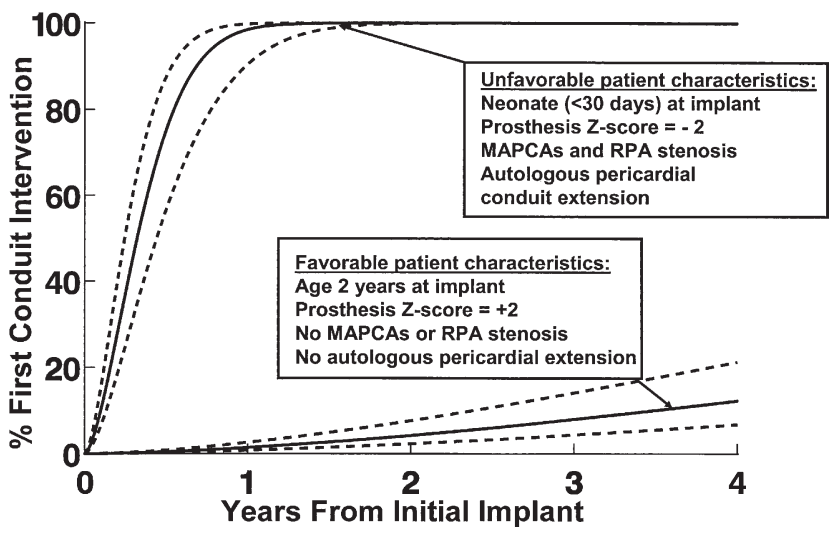

Figure E3. Two specific solutions to the multivariable equation for first conduit intervention show the influence of the age at initial implant on the rate intervention at 2 years after initial implantation. For a patient undergoing initial conduit implant at 2 years of age with an initial PC Z-score of +2 , with favorable pulmonary arterial anatomy and no conduit extension or use of material other than autologous pericardium for the extension, conduit intervention is below $20 \%$ even at 4 years after initial implant. However, for a patient with pulmonary arterial arborization abnormalities undergoing initial conduit implant in the neonatal period with the use of an undersized conduit and an autologous pericardial extension hood, of the predicted prevalence of conduit-related intervention within 1 year of initial conduit implantation is $100 \%$. Solid lines are parametric point estimates enclosed by dashed confidence limits equivalent to 1 standard error (68\%). MAPCAs, Major aortopulmonary collateral arteries; $R P A$, right pulmonary artery.

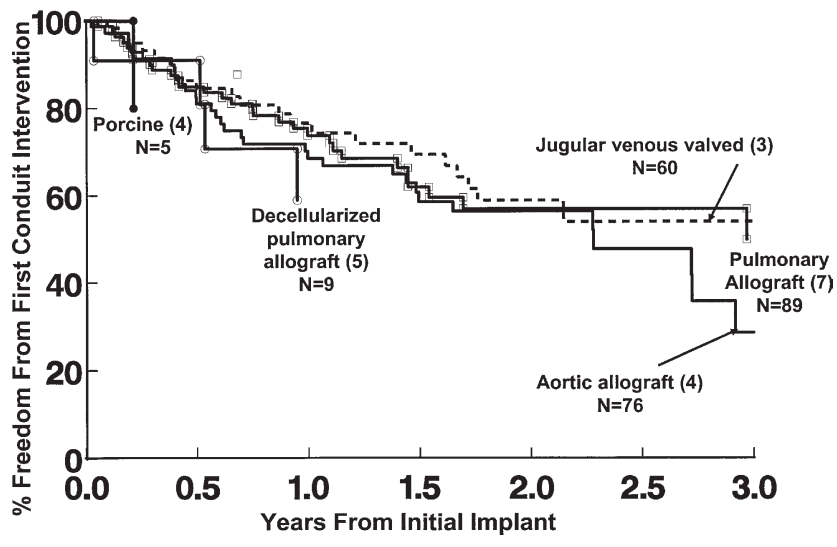

Figure E4. Kaplan-Meier estimated freedom from first conduitrelated intervention stratified by conduit type. Freedom from first intervention was not significantly related to the type of initial conduit ( $\boldsymbol{P}=.92$; Wilcoxon), although follow-up intervals are short for some of the conduit types. $\boldsymbol{N}$ is the number of patients beginning within each stratum, and the numbers in parentheses are the number of children remaining at risk at the last event-time within 3 years of follow-up.

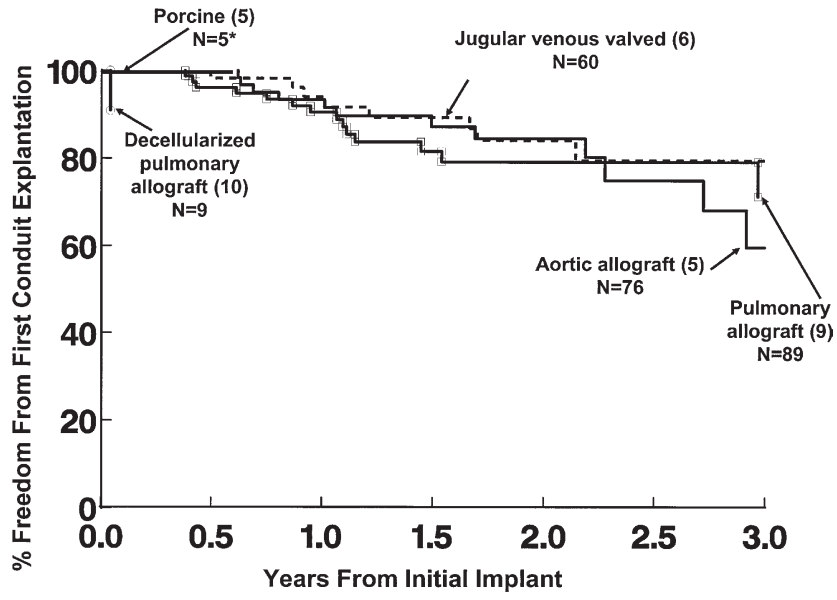

Figure E5. Kaplan-Meier estimated freedom from conduit explantation stratified by conduit type. Freedom from explant was not significantly related to the type of initial conduit $(P=0.81$; Wilcoxon), although follow-up intervals are short for some of the conduit types. $\boldsymbol{N}$ is the number of patients beginning within each stratum, and the numbers in parentheses are the number of children remaining at risk at the last event-time within 3 years of follow-up. 
TABLE E3. Factors associated with longitudinal changes in conduit function

\begin{tabular}{|c|c|c|}
\hline Variable & Parameter estimate $( \pm \mathrm{SE})$ & $\boldsymbol{P}$ \\
\hline \multicolumn{3}{|l|}{ 1. Increased PC peak Doppler gradient } \\
\hline Longer time interval from initial PC* & $30.75 \pm 4.46$ & $<.001$ \\
\hline Smaller initial PC Z-score† & $1.79 \pm 0.57$ & .002 \\
\hline Use of an aortic allograftł & $15.91 \pm 6.17$ & .01 \\
\hline Use of a proximal noncircumferential autologous pericardial extension & $6.47 \pm 2.71$ & .007 \\
\hline \multicolumn{3}{|l|}{ 2. Higher grade of $\mathrm{PC}$ regurgitation } \\
\hline Longer time interval from initial PC§ & $0.46 \pm 0.05$ & $<.001$ \\
\hline Younger age at initial PC implant & $1.55 \pm 0.27$ & $<.001$ \\
\hline Larger initial PC Z-score $\|$ & $0.02 \pm 0.01$ & .004 \\
\hline Non-use of a bovine jugular venous valved conduit $\ddagger$ & $0.80 \pm 0.26$ & .002 \\
\hline Use of an aortic allograft & $0.55 \pm 0.27$ & .053 \\
\hline
\end{tabular}

$S E$, Standard error; $P C$, pulmonary conduit. *After inverse transformation. †Complex polynomial term consisting of the inverse of the exponentiated term followed by square transformation. $\ddagger$ Interaction term between conduit type and time; robust standard-errors using sandwich estimator are reported as cluster size $>200$. §After logarithmic transformation. \|After exponential transformation.

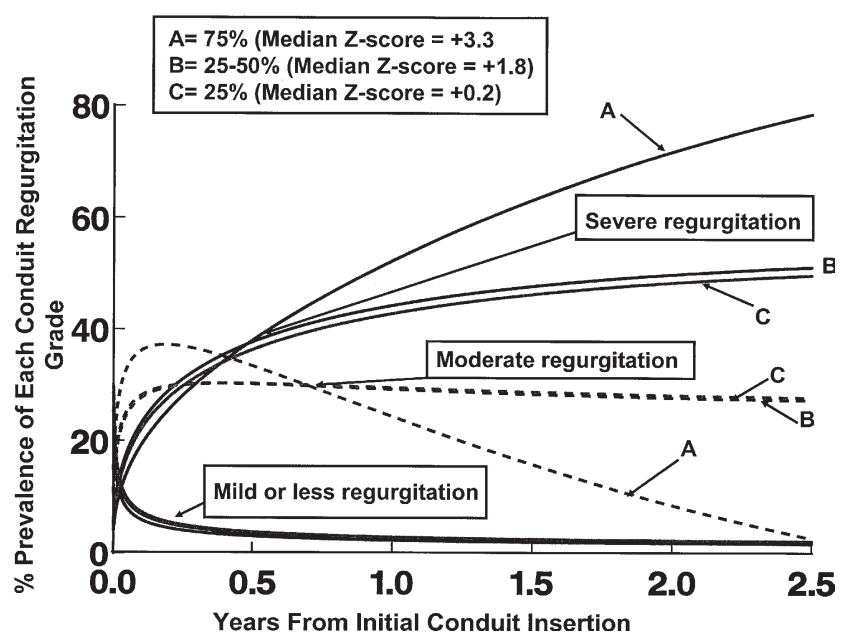

Figure E6. Risk-adjusted estimates of the proportion of patients who will exist in each subjective grade of regurgitation over time stratified by quartiles of the initial conduit Z-score. For clarity, the middle 2 quartiles have been condensed into a single group. The largest upper $75 \%$ quartile, corresponding to a median initial conduit Z-score of +3 , was associated with more rapid progression to a more severe grade of conduit regurgitation after adjustment for other predictors.
TABLE E4. List of participating institutions

The Children's Hospital at Boston
Children's Memorial, Chicago
Children's Hospital of Michigan
Children's Hospital of Philadelphia
Children's Hospital and Health Center, San Diego
Children's Hospital Wisconsin
Children's Mercy Hospital, Kansas City
Dupont Hospital for Children
The Emory Clinic
The Hospital for Sick Children, Toronto
Mott Children's Hospital
Milton Hershey Medical Center
Montreal Children's Hospital
Doernbecher Children's Hospital, Oregon Health Sciences
University
Primary Children's Hospital
University of Chicago
University of Louisville

